\title{
Fuzzy g* Pre- Continuous Maps in Fuzzy Topological Spaces
}

\author{
S. S. Benchalli \\ Professor \\ Department of Mathematics \\ Karnatak University. Dharwad \\ Karnataka State, India
}

\author{
G. P. Siddapur \\ Research Scholar \\ Department of Mathematics \\ Karnatak University. Dharwad \\ Karnataka State, India
}

\begin{abstract}
A new form of fuzzy $g^{*} p$-continuous, fuzzy $g^{*} p$ irresolute mappings, fuzzy $g^{*} p$-closed maps and fuzzy $g^{*} p$ open maps in fuzzy topological spaces are introduced and their properties have been investigated. As an application of these mappings Tp-spaces,gp-homeomorphism are introduced and investigated.
\end{abstract}

\section{AMS Subject Classification 54A40.}

\section{Keywords}

$g^{*} p$-closed fuzzy sets, fuzzy $g^{*} p$-continuous, fuzzy $g^{*} p$ irresolute mappings, fuzzy $g^{*} p$-closed maps and fuzzy $g^{*} p$ open maps

\section{INTRODUCTION}

The concept of fuzzy sets and fuzzy set operations were first introduced by L. A. Zadeh in his classical paper [13] in the year 1965. Subsequently several researchers have worked on various basic concepts from general topology using fuzzy sets and developed the theory of fuzzy topological spaces. The notion of fuzzy sets naturally plays a very significant role in the study of fuzzy topology introduced by C. L.Chang [4]. N. Levine [7] introduced the concepts of generalized closed sets in general topology in the year 1970. T. Fukutake, R.K. Saraf, M. Caldas and S. Mishra [6] introduced generalized preclosed fuzzy (briefly gp - closed) sets in fuzzy topological space. In 2002, g*p-closed sets, g*p-continuous, g*pirresolute, $\mathrm{g} * \mathrm{p}$-closed, $\mathrm{g} * \mathrm{p}$-open maps and $\mathrm{T}_{\mathrm{p}} *{ }^{*} \mathrm{~T}_{\mathrm{p}}$-spaces were introduced and studied by M.K.R.S. Veerakumar [12] for general topology.

In this paper, we introduce fuzzy $\mathrm{g}^{*} \mathrm{p}$-continuous, fuzzy $g^{*}$ p-irresolute mappings, fuzzy $\mathrm{g}^{*}$-closed maps and fuzzy g*p-open maps in fuzzy topological spaces. Some of their properties have been investigated.

\section{BASIC CONCEPTS}

A family $\mathrm{T}$ of fuzzy sets of $\mathrm{X}$ is called a fuzzy topology on $\mathrm{X}$ if 0 and 1 belong to $\mathrm{T}$ and $\mathrm{T}$ is closed with respect to arbitrary union and finite intersection. The members of $\mathrm{T}$ are called open fuzzy sets and their compliments are closed fuzzy sets. Let $\mathrm{X}, \mathrm{Y}$ and $\mathrm{Z}$ be sets. Throughout the present paper (X, T), $(\mathrm{Y}, \sigma)$ and $(\mathrm{Z}, \eta$ ) (or simply $\mathrm{X}, \mathrm{Y}$ and $\mathrm{Z}$ ) mean fuzzy topological spaces (abbreviated as fts) on which no separation axioms are assumed unless explicitly stated. Let A be a fuzzy set of $\mathrm{X}$. We denote the closure and interior of $\mathrm{A}$ by $\operatorname{cl}(\mathrm{A})$ and int(A) respectively.

\subsection{Definition A fuzzy set A of a fts $(\mathrm{X}, \mathrm{T})$ is called:}

1. a semi - open fuzzy set [1] if $\mathrm{A} \leq \mathrm{cl}(\operatorname{int}(\mathrm{A}))$ and a semi closed fuzzy set if int(cl(A)) $\leq \mathrm{A}$.

2. a pre - open fuzzy set [3] if $\mathrm{A} \leq \operatorname{int}(\mathrm{cl}(\mathrm{A}))$ and a pre closed fuzzy set if $\operatorname{cl}(\operatorname{int}(\mathrm{A})) \leq \mathrm{A}$.

3. a $\alpha$ - open fuzzy set [3] if $\mathrm{A} \leq \operatorname{int}(\operatorname{cl}(\operatorname{int}(\mathrm{A})))$ and a $\alpha-$ closed fuzzy set if $\operatorname{cl}(\operatorname{int}(\operatorname{cl}(\mathrm{A}))) \leq \mathrm{A}$.

The semi - closure (resp. preclosure, $\alpha$ - closure) of a fuzzy set $\mathrm{A}$ in a $\mathrm{fts}(\mathrm{X}, \mathrm{T})$ is the intersection of all semi - closed (resp. preclosed fuzzy sets, $\alpha$ - closed fuzzy sets) fuzzy sets containing A and is denoted by $\operatorname{scl}(\mathrm{A})$ (resp. pcl (A), $\alpha \mathrm{cl}(\mathrm{A})$ ).

2.2 Definition A fuzzy set A in a fts $(\mathrm{X}, \mathrm{T})$ is called semipre open fuzzy set (briefly sp-open) [11] if there exists a pre - open fuzzy set $\mathrm{B}$ such that $\mathrm{B} \leq \mathrm{A} \leq \mathrm{cl}(\mathrm{B})$.

The compliment of $\mathrm{sp}-$ open fuzzy set is called semi pre closed fuzzy ( $\mathrm{sp}$ - closed) set. Semi pre - closure and semipre - interior of a fuzzy set $\mathrm{A}$ is defined as : $\operatorname{spcl}(A)=\wedge\{B: A \leq B, B$ is sp-closed fuzzy set in $X\}$ $\operatorname{spint}(\mathrm{A})=\vee\{\mathrm{B}: \mathrm{B} \leq \mathrm{A}, \mathrm{B}$ is sp-open fuzzy set in $\mathrm{X}\}$ The following definitions are useful in the sequel.

2.3 Definition A fuzzy set A of a fts (X, T) is called:

1. a generalized closed ( $\mathrm{g}$ - closed) fuzzy set [2] if $\operatorname{cl}(\mathrm{A}) \leq$ $\mathrm{U}$ whenever $\mathrm{A} \leq \mathrm{U}$ and $\mathrm{U}$ is open fuzzy set in $(\mathrm{X}, \mathrm{T})$.

2. a generalized - preclosed (gp - closed) fuzzy set [6] if $\operatorname{pcl}(\mathrm{A}) \leq \mathrm{U}$ whenever $\mathrm{A} \leq \mathrm{U}$ and $\mathrm{U}$ is open fuzzy set in $(\mathrm{X}, \mathrm{T})$.

3. a generalized semi - pre closed (gsp - closed) fuzzy set [8] if $\operatorname{spcl}(\mathrm{A}) \leq \mathrm{U}$ whenever $\mathrm{A} \leq \mathrm{U}$ and $\mathrm{U}$ is open fuzzy set in $(X, T)$.

4. a g*- closed fuzzy set [7] if $\operatorname{cl}(\mathrm{A}) \leq \mathrm{U}$ whenever $\mathrm{A} \leq \mathrm{U}$ and $\mathrm{U}$ is $\mathrm{g}-$ open fuzzy set in $(\mathrm{X}, \mathrm{T})$.

Complements of $\mathrm{g}$ - closed fuzzy (resp. gp - closed fuzzy set, gsp - closed fuzzy set and $\mathrm{g}^{*}$-closed fuzzy set) sets are called g-open (resp.gp - open fuzzy set, gsp - open fuzzy set and $\mathrm{g}^{*}$ - open fuzzy set) set.

2.4 Definition Let $\mathrm{X}, \mathrm{Y}$ be two fuzzy topological spaces. A function $\mathrm{f}: \mathrm{X} \rightarrow \mathrm{Y}$ is called

1) fuzzy continuous (f-continuous) [4] if $\mathrm{f}^{-1}(\mathrm{~B})$ is open fuzzy set in $X$, for every open fuzzy set $B$ of $Y$

2) fuzzy pre-continuous (fp-continuous) function [3] if $f$ ${ }^{1}$ (A) is pre - open fuzzy set in $\mathrm{X}$, for every - open fuzzy set $\mathrm{A}$ of $\mathrm{Y}$.

3) fg-continuous function [2] if $f^{-1}(A)$ is $g$ - closed fuzzy set in $\mathrm{X}$, for every closed fuzzy set $\mathrm{A}$ of $\mathrm{Y}$.

4) fgsp - continuous function [8] if $\mathrm{f}^{-1}(\mathrm{~A})$ is gsp - closed fuzzy set in $X$, for every closed fuzzy set $A$ of $Y$.

5) fgp - continuous functions [6]if $\mathrm{f}^{-1}(\mathrm{~A})$ is gp - closed fuzzy set in $\mathrm{X}$, for every closed fuzzy set $\mathrm{A}$ of $\mathrm{Y}$.

6) $\mathrm{fg}^{*}$ - continuous function [7] if $\mathrm{f}^{-1}(\mathrm{~A})$ is $\mathrm{g}^{*}$ - closed fuzzy set in $\mathrm{X}$, for every closed fuzzy set $\mathrm{A}$ of $\mathrm{Y}$. 
2.5 Definition A fuzzy topological space $(\mathrm{X}, \mathrm{T})$ is called a

1. fuzzy $T_{1 / 2^{-}}$space [2] if every $\mathrm{g}$ - closed fuzzy set in $\mathrm{X}$ is a closed fuzzy set in X.

2. fuzzy $\mathrm{T}^{*}{ }_{1 / 2}$ space [7 ] if every $\mathrm{g}^{*}$ - closed fuzzy set is a closed fuzzy set.

\section{FUZZY g*p-CONTINUOUS MAPS IN FTS}

In this section, we introduce fuzzy $g * p$-continuous maps, fuzzy $g^{*} p$-irresolute maps, fuzzy $g^{*} p$-closed maps, fuzzy $\mathrm{g}^{*} \mathrm{p}$-open maps and fuzzy $\mathrm{g}$ *p-homoeomorphisms in fuzzy topological spaces and study some of their properties.

3.1 Definition A fuzzy set A of a fts $(\mathrm{X}, \mathrm{T})$ is called a $\mathrm{g}^{*}$ pre-closed fuzzy (briefly $\mathrm{g}^{*} \mathrm{p}$-closed) set if $\operatorname{pcl}(\mathrm{A}) \leq \mathrm{U}$ whenever $\mathrm{A} \leq \mathrm{U}$ and $\mathrm{U}$ is $\mathrm{g}$ - open fuzzy set in $(\mathrm{X}, \mathrm{T})$.

3.2 Definition A fuzzy set $\mathrm{A}$ of a $\mathrm{fts}(\mathrm{X}, \mathrm{T})$ is called a $\mathrm{g}^{*}$ pre-open ( $g^{*}$ p-open) fuzzy set if its complements $1-\mathrm{A}$ is $\mathrm{g}^{*} \mathrm{p}$ closed fuzzy set.

3.3 Definition Let $\mathrm{X}$ and $\mathrm{Y}$ be fuzzy topological spaces. A map $\mathrm{f}: \mathrm{X} \rightarrow \mathrm{Y}$ is said to be fuzzy $\mathrm{g}^{*} \mathrm{p}$-continuous (briefly fg*p-continuous) if the inverse image of every open fuzzy set in $\mathrm{Y}$ is $\mathrm{g}^{*} \mathrm{p}$-open fuzzy set in $\mathrm{X}$.

3.4 Theorem A function $\mathrm{f}: \mathrm{X} \rightarrow \mathrm{Y}$ is fg* $\mathrm{p}$-continuous if and only if the inverse image of every closed fuzzy set in $\mathrm{Y}$ is $\mathrm{g}^{*} \mathrm{p}$-closed fuzzy in $\mathrm{Y}$.

3.5 Theorem Every f-continuous function is fg*pcontinuous function

Proof Let $\mathrm{f}: \mathrm{X} \rightarrow \mathrm{Y}$ be a f-continuous function. Let $\mathrm{V}$ be an open fuzzy set in $\mathrm{Y}$. Since $\mathrm{f}$ is $\mathrm{f}$-continuous, $\mathrm{f}^{-1}(\mathrm{~V})$ is open in $X$. And so $f^{-1}(V)$ is $g^{*} p$-open fuzzy set in $X$. Therefore $f$ is fg*p-continuous function.

The converse of the above theorem need not be true as seen from the following example.

3.6 Example Let $\mathrm{X}=\mathrm{Y}=\{\mathrm{a}, \mathrm{b}, \mathrm{c}\}$ and the fuzzy sets $\mathrm{A}$ and $\mathrm{B}$ be defined as follows: $\quad \mathrm{A}=\{(\mathrm{a}, 1),(\mathrm{b}, 0.9),(\mathrm{c}, 0.8)\}$, $\mathrm{B}=\{(\mathrm{a}, 0.4),(\mathrm{b}, 0.5),(\mathrm{c}, 0.6)\}$. Consider $\mathrm{T}=\{0,1, \mathrm{~A}\}$ and $\sigma=$ $\{0,1, \mathrm{~B}\}$. Then $(\mathrm{X}, \mathrm{T})$ and $(\mathrm{Y}, \sigma)$ are fts. Let $\mathrm{f}: \mathrm{X} \rightarrow \mathrm{Y}$ be the identity map. Then $f$ is fg*p-continuous map but not fuzzycontinuous, since the open fuzzy set $\mathrm{B}$ in $\mathrm{Y}, \mathrm{f}^{-1}(\mathrm{~B})=\mathrm{C}$ is not closed fuzzy set in $\mathrm{X}$ but it is $\mathrm{g}^{*} \mathrm{p}$-closed in $\mathrm{X}$.

3.7 Theorem (1) Every fg*p-continuous function is fgpcontinuous function.

(2) Every fg*p-continuous function is fgsp continuous function.

Proof Straight forward and follows from the definitions.

The converse of the above theorem need not be true as seen from the following example.

3.8 Example Let $\mathrm{X}=\mathrm{Y}=\{\mathrm{a}, \mathrm{b}, \mathrm{c}\}$ and the fuzzy sets $\mathrm{A}, \mathrm{B}$ and $\mathrm{C}$ be defined as follows: $\mathrm{A}=\{(\mathrm{a}, 1),(\mathrm{b}, 0.9),(\mathrm{c}, 0.8)\}$, $\mathrm{B}=\{(\mathrm{a}, 0.4),(\mathrm{b}, 0.6),(\mathrm{c}, 0.8)\}$ and $\mathrm{C}=\{(\mathrm{a}, 0.6),(\mathrm{b}, 0.8),(\mathrm{c}$, $0.4)\}$. Consider $T=\{0,1, A\}=\sigma$. Then $(X, T)$ and $(Y, \sigma)$ are fts. Define a map $\mathrm{f}: \mathrm{X} \rightarrow \mathrm{Y}$ by $\mathrm{f}(\mathrm{a})=\mathrm{b}, \mathrm{f}(\mathrm{b})=\mathrm{c}$ and $\mathrm{f}(\mathrm{c})=\mathrm{a}$ is fgp-continuous and fgsp-continuous but not a fg*p-continuous map, for the closed set $\mathrm{B}$ in $\mathrm{Y}, \mathrm{f}^{-1}(\mathrm{~B})=\mathrm{C}$ is not $\mathrm{g}^{*} \mathrm{p}$-closed fuzzy set in $\mathrm{X}$.

3.9 Theorem A function $\mathrm{f}: \mathrm{X} \rightarrow \mathrm{Y}$ is fg*p-continuous and $\mathrm{X}$ is fuzzy $-\mathrm{T}_{\mathrm{p}}{ }^{*}$-space. Then $\mathrm{f}$ is $\mathrm{f}$-continuous.
Proof Let $\mathrm{F}$ be closed fuzzy set in $\mathrm{Y}$. Then $\mathrm{f}^{-1}(\mathrm{~F})$ is $\mathrm{g}^{*} \mathrm{p}$ closed fuzzy set in $X$. Since $X$ is fuzzy $-T_{p}{ }^{*}$ - space, $f^{-1}(F)$ is closed fuzzy set in $\mathrm{X}$. Thus $\mathrm{f}$ is $\mathrm{f}$-continuous function.

3.10 Theorem A function $\mathrm{f}: \mathrm{X} \rightarrow \mathrm{Y}$ is fgp-continuous and $\mathrm{X}$ is fuzzy $-* \mathrm{~T}_{\mathrm{p}}$-space. Then $\mathrm{f}$ is $\mathrm{fg} * \mathrm{p}$-continuous.

Proof Let $\mathrm{F}$ be closed fuzzy set in $\mathrm{Y}$. Then $\mathrm{f}^{-1}(\mathrm{~F})$ is gpclosed fuzzy set in $\mathrm{X}$. Since $\mathrm{X}$ is fuzzy $-* \mathrm{~T}_{\mathrm{p}}$ - space, $\mathrm{f}^{-1}(\mathrm{~F})$ is $\mathrm{g}^{*} \mathrm{p}$-closed fuzzy set in $\mathrm{X}$. Thus $\mathrm{f}$ is $\mathrm{fg}$ * $\mathrm{p}$-continuous function.

3.11 Theorem If $\mathrm{f}: \mathrm{X} \rightarrow \mathrm{Y}$ is fg*p-continuous and $\mathrm{g}: \mathrm{Y} \square \rightarrow$ $\mathrm{Z}$ is fg*p-continuous and $\mathrm{Y}$ is fuzzy $-\mathrm{T}_{\mathrm{p}}{ }^{*}$ - space. Then gof: $\mathrm{X} \square \rightarrow \mathrm{Z}$ is fg*p-continuous.

Proof Let $\mathrm{F}$ be closed fuzzy set in $\mathrm{Z}$. Then $\mathrm{g}^{-1}(\mathrm{~F})$ is $\mathrm{g}^{*} \mathrm{p}$ closed fuzzy set in $Y$. Since $Y$ is fuzzy $-T_{p}{ }^{*}$ - space, $g^{-1}(F)$ is closed fuzzy set in $Y$. Then $\mathrm{f}^{-1}\left(\mathrm{~g}^{-1}(\mathrm{~F})\right)$ is $\mathrm{g}^{*} \mathrm{p}$-closed in fuzzy $\mathrm{X}$ as $\mathrm{f}$ is $\mathrm{fg}^{*} \mathrm{p}$-continuous. Thus gof is $\mathrm{fg} * \mathrm{p}$-continuous function.

3.12 Definition A function $\mathrm{f}: \mathrm{X} \rightarrow \mathrm{Y}$ is said to be fuzzy $\mathrm{g}^{*} \mathrm{p}$ - irresolute (briefly fg*p - irresolute) if the inverse image of every $\mathrm{g}^{*} \mathrm{p}$-closed fuzzy set in $\mathrm{Y}$ is $\mathrm{g}^{*} \mathrm{p}$-closed fuzzy set in $\mathrm{X}$.

3.13 Theorem A function $\mathrm{f}: \mathrm{X} \rightarrow \mathrm{Y}$ is $\mathrm{fg}^{*} \mathrm{p}$-irresolute function if and only if the inverse image of every $g^{*} p$ - open fuzzy set in $\mathrm{Y}$ is $\mathrm{g}^{*} \mathrm{p}$-open fuzzy set in $\mathrm{X}$.

3.14 Theorem Every fg*p-irresolute function is fg*pcontinuous function.

Proof Let $\mathrm{f}: \mathrm{X} \rightarrow \mathrm{Y}$ is fg*p-irresolute function. Let $\mathrm{F}$ be a closed fuzzy set in $\mathrm{Y}$, Then $\mathrm{F}$ is $\mathrm{g}^{*} \mathrm{p}$-closed fuzzy set in $\mathrm{Y}$. Since $\mathrm{f}$ is $\mathrm{fg}^{*} \mathrm{p}$-irresolute, $\mathrm{f}^{-1}(\mathrm{~V})$ is a $\mathrm{g}^{*} \mathrm{p}$-closed fuzzy set in $X$. Hence $\mathrm{f}$ is $\mathrm{fg}^{*} \mathrm{p}$-continuous function.

The converse of the above theorem need not be true as seen from the following example.

3.15 Example Let $\mathrm{X}=\mathrm{Y}=\{\mathrm{a}, \mathrm{b}, \mathrm{c}\}$ and the fuzzy sets $\mathrm{A}, \mathrm{B}$, $\mathrm{C}, \mathrm{D}$ and $\mathrm{E}$ be defined as follows. $\mathrm{A}=\{(\mathrm{a}, 0.9),(\mathrm{b}, 0.9)$, (c, $1)\}, B=\{(a, 0.8),(b, 0.5),(c, 0.6)\}, C=\{(a, 0.7),(b, 0.5),(c$, $0.6)\}, \mathrm{D}=\{(\mathrm{a}, 0.5),(\mathrm{b}, 0.2),(\mathrm{c}, 0.3)\}, \mathrm{E}=\{(\mathrm{a}, 0.5),(\mathrm{b}, 0.6),(\mathrm{c}$, $0.7)\}$. Consider $T=\{0,1, A, B, C, D\}$ and $\sigma=\{0,1, C\}$. Then $(\mathrm{X}, \mathrm{T})$ and $(\mathrm{Y}, \sigma)$ are fts. Define $\mathrm{f}: \mathrm{X} \rightarrow \mathrm{Y}$ by $\mathrm{f}(\mathrm{a})=\mathrm{c}$, $f(b)=a$ and $f(c)=b$. Then $f$ is fg*p-continuous but not fg*pirresolute as the fuzzy set $E$ is $g^{*} p$-closed fuzzy set in $Y$, but $f$ ${ }^{-1}(\mathrm{E})=\mathrm{C}$ is not $\mathrm{g}^{*} \mathrm{p}$-closed fuzzy set in $\mathrm{X}$.

3.16 Theorem Let $\mathrm{f}: \mathrm{X} \rightarrow \mathrm{Y}, \mathrm{g}: \mathrm{Y} \square \rightarrow \mathrm{Z}$ be two functions. Then

(1) gof: $\mathrm{X} \square \rightarrow \mathrm{Z}$ is fg*p-continuous, if $\mathrm{f}$ is $\mathrm{fg}$ * $\mathrm{p}$-continuous and $g$ are $f$-continuous.

(2) gof: $X \square \rightarrow Z$ is fg*p- irresolute, if $f$ and $g$ are fg*pirresolute functions.

(3) gof: $X \square \rightarrow Z$ is fg*p - continuous if $\mathrm{f}$ is fg*p- irresolute and $g$ is $\mathrm{fg}^{*} \mathrm{p}$-continuous.

3.17 Theorem If $\mathrm{f}: \mathrm{X} \rightarrow \mathrm{Y}, \mathrm{g}: \mathrm{Y} \square \rightarrow \mathrm{Z}$ be two fuzzy functions. If $\mathrm{f}$ is $\mathrm{fg}^{*} \mathrm{p}$ - continuous and $\mathrm{g}$ is $\mathrm{fg}^{*} \mathrm{p}$-irresolute and $\mathrm{Y}$ is fuzzy $-\mathrm{T}_{\mathrm{p}}$ *- $_{-}$space, then gof: $\mathrm{X} \square \rightarrow \mathrm{Z}$ is fg*p irresolute function.

Proof Let $\mathrm{F}$ be $\mathrm{g}^{*} \mathrm{p}$-closed fuzzy set in $\mathrm{Z}$. Then $\mathrm{g}^{-1}(\mathrm{~F})$ is $\mathrm{g}^{*} \mathrm{p}$ closed fuzzy set in $Y$, as $g$ is f $g^{*} p$-irresolute. Since $Y$ is fuzzy $-T_{p}{ }^{*}$ - space, $g^{-1}(F)$ is closed fuzzy set in $Y$. Again since $f$ is fg*p-continuous, $f^{-1}\left(g^{-1}(F)\right)=(g o f)^{-1}(F)$ is $g^{*} p$-closed fuzzy set in $\mathrm{X}$. Hence gof is $\mathrm{fg}^{*} \mathrm{p}$-irresolute function. 
3.18 Theorem Let $\mathrm{f}: \mathrm{X} \rightarrow \mathrm{Y}$ be a fg* ${ }^{*}$-continuous function and $\mathrm{Y}$ is fuzzy $-\mathrm{T}_{\mathrm{p}}{ }^{*}$ - space, then $\mathrm{f}$ is $\mathrm{fg} * \mathrm{p}$ - irresolute function. Proof Let F be g*p-closed fuzzy set in Y. Then F is closed fuzzy set in $Y$ as $Y$ is fuzzy $-T_{p}{ }^{*}$ - space. Since $f$ is fg*pcontinuous, we have $f^{-1}(F)$ is $g^{*} p$-closed in $X$. And hence $f$ is $\mathrm{fg}^{*} \mathrm{p}$-irresolute function.

3.19 Theorem Let $\mathrm{f}: \mathrm{X} \rightarrow \mathrm{Y}$ be an onto, fg*p-irresolute and a closed map. If $\mathrm{X}$ is a fuzzy $-\mathrm{T}_{\mathrm{p}}{ }^{*}$ - space, then $\mathrm{Y}$ is also fuzzy $-\mathrm{T}_{\mathrm{p}}{ }^{*}$ - space.

Proof Let $\mathrm{F}$ be $\mathrm{g}^{*} \mathrm{p}$-closed fuzzy set in $\mathrm{Y}$. Then $\mathrm{f}^{-1}(\mathrm{~F})$ is $\mathrm{g}^{*} \mathrm{p}$ closed in $X$ as $f$ is $f g^{*} p$-irresolute. Since $X$ is fuzzy $-T_{p}{ }^{*}$ space, $\mathrm{f}^{-1}(\mathrm{~F})$ is closed in $\mathrm{X}$. And so $\mathrm{f}\left(\mathrm{f}^{-1}(\mathrm{~F})\right)=\mathrm{F}$ is closed in $\mathrm{Y}$ as $\mathrm{f}$ is closed and onto function. Hence $\mathrm{Y}$ is fuzzy $-\mathrm{T}_{\mathrm{p}}{ }^{*_{-}}$ space.

3.20 Definition A function $\mathrm{f}: \mathrm{X} \rightarrow \mathrm{Y}$ is said to be fuzzy $\mathrm{g}^{*} \mathrm{p}$-open (briefly fg*p-open) map if the image of every open fuzzy set in $\mathrm{X}$ is $\mathrm{g}^{*} \mathrm{p}$ - open fuzzy set in $\mathrm{Y}$.

3.21 Definition A function $\mathrm{f}: \mathrm{X} \rightarrow \mathrm{Y}$ is said to be fuzzy $\mathrm{g}^{*}$-closed (briefly fg*p-closed) map if the image of every closed fuzzy set in $\mathrm{X}$ is $\mathrm{g}^{*} \mathrm{p}$-closed fuzzy set in $\mathrm{Y}$.

3.22 Theorem If $\mathrm{f}: \mathrm{X} \rightarrow \mathrm{Y}$ is a fuzzy $\mathrm{g}^{*} \mathrm{p}$ - open map and $\mathrm{Y}$ is fuzzy- $\mathrm{T}_{\mathrm{p}}{ }^{*}$ - space, then $\mathrm{f}$ is a $\mathrm{f}$ - open map.

Proof Let V be an open fuzzy set in $\mathrm{X}$. Then $\mathrm{f}(\mathrm{V})$ is $\mathrm{g}^{*} \mathrm{p}$ open fuzzy set in $\mathrm{Y}$ since $\mathrm{f}$ is $\mathrm{fg}^{*} \mathrm{p}$ - open map. Again since $\mathrm{Y}$ is fuzzy- $T_{p}{ }^{*}$ - space, $f(V)$ is open fuzzy set in $Y$. Hence $f: X \rightarrow$ $\mathrm{Y}$ be a f-open map.

3.23 Theorem If $\mathrm{f}: \mathrm{X} \rightarrow \mathrm{Y}$ be a fg*p- closed map and $\mathrm{Y}$ is fuzzy- $\mathrm{T}_{\mathrm{p}} *$ - space, then $\mathrm{f}$ is a f-closed map.

3.24 Theorem A map $\mathrm{f}: \mathrm{X} \rightarrow \mathrm{Y}$ is fg*p-closed if and only if for each fuzzy set $\mathrm{S}$ of $\mathrm{Y}$ and for each open fuzzy set $\mathrm{U}$ such that $f^{-1}(S) \leq U$, there is a $g^{*} p$ - open fuzzy set $V$ of $Y$ such that $\mathrm{S} \leq \mathrm{V}$ and $\mathrm{f}^{-1}(\mathrm{~V}) \leq \mathrm{U}$.

Proof Suppose $\mathrm{f}$ is fg*p- closed map. Let $\mathrm{S}$ be a fuzzy set of $\mathrm{Y}$, and $\mathrm{U}$ be an open fuzzy set of $\mathrm{X}$, such that $\mathrm{f}^{-1}(\mathrm{~S}) \leq \mathrm{U}$. Then $V=Y-f(X-U)$ is a $g^{*} p$ - open fuzzy set in $Y$ such that $S \leq$ $\mathrm{V}$ and $\mathrm{f}^{-1}(\mathrm{~V}) \leq \mathrm{U}$.

Conversely, suppose that $\mathrm{F}$ is a closed fuzzy set of $\mathrm{X}$. Then $\mathrm{f}^{-1}(\mathrm{Y}-\mathrm{f}(\mathrm{F})) \leq \mathrm{X}-\mathrm{F}$, and $\mathrm{X}-\mathrm{F}$ is open fuzzy set. By hypothesis, there is a $\mathrm{g}^{*} \mathrm{p}$ - open fuzzy set $\mathrm{V}$ of $\mathrm{Y}$ such that $\mathrm{Y}$ $\mathrm{f}(\mathrm{X}-\mathrm{U}) \leq \mathrm{V}$ and $\mathrm{f}^{-1}(\mathrm{~V}) \leq \mathrm{X}-\mathrm{F}$. Therefore $\mathrm{F} \leq \mathrm{X}-\mathrm{f}^{-1}(\mathrm{~V})$. Hence $\mathrm{Y}-\mathrm{V} \leq \mathrm{f}(\mathrm{V}) \leq \mathrm{f}\left(\mathrm{X}-\mathrm{f}^{-1}(\mathrm{~V})\right) \leq \mathrm{Y}-\mathrm{V}$, which implies $\mathrm{f}(\mathrm{F})=\mathrm{Y}-\mathrm{V}$. Since $\mathrm{Y}-\mathrm{V}$ is $\mathrm{g}^{*} \mathrm{p}$ - closed fuzzy set, $\mathrm{f}(\mathrm{F})$ is $\mathrm{g}^{*} \mathrm{p}$ - closed fuzzy set and thus $\mathrm{f}$ is a fg* $\mathrm{p}$ - closed fuzzy map.

3.25 Theorem If $\mathrm{f}: \mathrm{X} \rightarrow \mathrm{Y}$ is f-closed map and $\mathrm{g}: \mathrm{Y} \rightarrow \mathrm{Z}$ is fg*p - closed maps, then gof: $X \rightarrow Z$ is fg*p-closed map.

3.26 Theorem If $\mathrm{f}: \mathrm{X} \rightarrow \mathrm{Y}$ and $\mathrm{g}: \mathrm{Y} \rightarrow \mathrm{Z}$ are $\mathrm{fg} * \mathrm{p}$ - closed maps and $\mathrm{Y}$ is fuzzy $-\mathrm{T}_{\mathrm{p}}$ *-space, then gof: $\mathrm{X} \rightarrow \mathrm{Z}$ is $\mathrm{f} \mathrm{g}^{*} \mathrm{p}$ closed map.

3.27 Theorem Let $\mathrm{f}: \mathrm{X} \rightarrow \mathrm{Y}, \mathrm{g}: \mathrm{Y} \rightarrow \mathrm{Z}$ be two maps such that gof: $X \rightarrow Z$ is $\mathrm{fg}^{*} \mathrm{p}$ - closed map. i) If $\mathrm{f}$ is fuzzy continuous and surjective, then $g$ is $f g^{*} p$ - closed map. closed map.

ii) If $g$ is $f * p$-irresolute and injective, then $f$ is $\mathrm{fg}^{*} \mathrm{p}$ -

Proof i) Let $\mathrm{G}$ be a closed fuzzy set of $\mathrm{Y}$. Then $\mathrm{f}^{-1}(\mathrm{G})$ is closed fuzzy set in $\mathrm{X}$ as $\mathrm{f}$ is fuzzy continuous. Since gof is fg*p-closed map, $($ gof $)\left(f^{-1}(G)\right)=g(G)$ is $g^{*} p$-closed fuzzy set in $Z$. Hence $g: Y \rightarrow Z$ fg*p - closed map.

ii) Let $F$ be a closed fuzzy set in $X$. Then (gof) $(F)$ is $g^{*} p-$ closed fuzzy set in $\mathrm{Z}$, and so $\mathrm{g}^{-1}(\mathrm{gof})(\mathrm{F})=\mathrm{f}(\mathrm{F})$ is $\mathrm{g}^{*} \mathrm{p}$-closed fuzzy set in Y. Since $g$ is $f g^{*} p$-irresolute and injective. Hence $f$ is a fg*p - closed map.

3.28 Theorem If $\mathrm{A}$ is $\mathrm{g}^{*} \mathrm{p}$-closed fuzzy set in $\mathrm{X}$ and $\mathrm{f}: \mathrm{X} \rightarrow$ $\mathrm{Y}$ is bijective, f-continuous and $\mathrm{fg}^{*} \mathrm{p}$-closed, then $\mathrm{f}(\mathrm{A})$ is $\mathrm{g}^{*} \mathrm{p}$ closed fuzzy set in $\mathrm{Y}$.

Proof Let $\mathrm{f}(\mathrm{A}) \leq \mathrm{O}$ where $\mathrm{O}$ is an open fuzzy set in $\mathrm{Y}$. Since $\mathrm{f}$ is $\mathrm{f}$-continuous, $\mathrm{f}^{-1}(\mathrm{O})$ is an open fuzzy set containing $\mathrm{A}$. Hence $\operatorname{pcl}(A) \leq \mathrm{f}^{1}(\mathrm{O})$ as $A$ is $\mathrm{g}^{*} \mathrm{p}$-closed fuzzy set. since $\mathrm{f}$ is fg*p-closed, $f(p c l(A))$ is $g^{*} p$-closed fuzzy set contained in the open fuzzy set $\mathrm{O}$. Which implies $\operatorname{pcl}(\mathrm{f}(\operatorname{pcl}(\mathrm{A}))) \leq \mathrm{O}$ and hence $\operatorname{pcl}(\mathrm{f}(\mathrm{A})) \leq \mathrm{O}$. So $\mathrm{f}(\mathrm{A})$ is fg*p-closed fuzzy set in $\mathrm{Y}$ We introduce the following.

3.29 Definition A function $\mathrm{f}: \mathrm{X} \rightarrow \mathrm{Y}$ is called fuzzy $\mathrm{g}^{*} \mathrm{p}$ homeomorphism (briefly fg*p - homeomorphism) if $\mathrm{f}^{*}$ and $\mathrm{f}^{-1}$ are $\mathrm{fg}^{*} \mathrm{p}$ - continuous.

3.30 Theorem Every $\mathrm{f}$ - homeomorphism is fg*phomeomorphism.

Proof Let $\mathrm{f}: \mathrm{X} \rightarrow \mathrm{Y}$ be fuzzy homeomorphism. Then $\mathrm{f}$ and $\mathrm{f}^{-1}$ are $\mathrm{f}$-continuous. Therefore $\mathrm{f}$ and $\mathrm{f}^{-1}$ are $f \mathrm{~g}^{*} \mathrm{p}-$ continuous. Hence $\mathrm{f}$ is $\mathrm{fg} * \mathrm{p}$ - homeomorphism

The converse of the above theorem need not be true as seen from the following example.

3.31 Example Let $\mathrm{X}=\mathrm{Y}=\{\mathrm{a}, \mathrm{b}, \mathrm{c}\}$ and the fuzzy sets $\mathrm{A}, \mathrm{B}$ and $\mathrm{C}$ be defined as follows. $\quad \mathrm{A}=\{(\mathrm{a}, 1),(\mathrm{b}, 0.8),(\mathrm{c}$, $0.8)\}, B=\{(a, 0.3),(b, 0.6),(c, 0.8)\}, C=\{(a, 0.4),(b, 0.6)$, (c, 0.8) $\}$. Consider $T=\{0,1, A\}$ and $\sigma=\{0,1, B\}$. Then $(X$, $\mathrm{T})$ and $(\mathrm{Y}, \sigma)$ are fts. Define $\mathrm{f}: \mathrm{X} \rightarrow \mathrm{Y}$ by $\mathrm{f}(\mathrm{a})=\mathrm{a}, \mathrm{f}(\mathrm{b})=\mathrm{c}$ and $f(c)=b$. Then $f$ is $f g^{*} p$-homeomorphism but not $f$ homeomorphism as $\mathrm{A}$ is open in $\mathrm{X} \mathrm{f}(\mathrm{A})=\mathrm{A}$ is not open in $\mathrm{Y}$. $\mathrm{f}^{-1}: \mathrm{Y} \square \rightarrow \mathrm{X}$ is not $\mathrm{f}$-continuous.

3.32 Theorem Let $\mathrm{f}: \mathrm{X} \rightarrow \mathrm{Y}$ be a bijective function. Then the following are equivalent:

a) $\mathrm{f}$ is $f g^{*} \mathrm{p}$ - homeomorphism.

b) $f$ is f $g^{*} p$ - continuous and fg*p- open maps

c) $\mathrm{f}$ is $\mathrm{fg}^{*} \mathrm{p}$-continuous and $\mathrm{fg} * \mathrm{p}$-closed maps.

Proof (a) $\Rightarrow$ (b): Let $\mathrm{f}$ be fg*p - homeomorphism. Then $\mathrm{f}$ and $\mathrm{f}^{-1}$ are fg*p - continuous. To prove that $\mathrm{f}$ is $\mathrm{fg}^{*} \mathrm{p}$ - open map. Let $U$ be an open fuzzy set in $X$. Since $f^{-1}: Y \rightarrow \square X$ fg*p- continuous, $\quad\left(f^{-1}\right)^{-1}(U)=f(U)$ is $f g^{*} p$ - open in $Y$. Therefore $f(U)$ is $f g^{*} p$ - open in $Y$. Hence $f g^{*} p$ - open map. (b) $\Rightarrow(a)$ : Let $f$ be $\mathrm{fg}^{*} \mathrm{p}$ - open and $\mathrm{fg} * \mathrm{p}$ - continuous map. To prove that $\mathrm{f}^{-1}: \mathrm{Y} \square \rightarrow \mathrm{X}$ is fg*p - continuous. Let $\mathrm{U}$ be an open fuzzy set in $X$. Then $f(U)$ is $f g^{*} p-$ open set in $Y$ since $f$ is fg*p - open map. Now $\left(f^{-1}\right)^{-1}(\mathrm{U})=\mathrm{f}(\mathrm{U})$ is $\mathrm{fg}^{*} \mathrm{p}$ - open set in $\mathrm{Y}$. Therefore $\mathrm{f}^{-1}: \mathrm{Y} \square \rightarrow \mathrm{X}$ is fg* $\mathrm{p}$ - continuous. Hence $\mathrm{f}$ is fg*p - homeomorphism.

(b) $\Rightarrow$ (c): Let $\mathrm{f}$ be $\mathrm{fg} * \mathrm{p}$ - continuous and fg*p - open map. To prove that $f$ is $f g^{*} p$ - closed map. Let $F$ be a closed fuzzy set in $X$. Then $1-F$ is open fuzzy set in $X$. Since $f$ is $f g^{*} p$ - open map, $f(1-F)$ is $g^{*} p-$ open fuzzy set in $Y$. Now $f(1-F)=1-f(F)$. Therefore $f(F)$ is $f g * p$-closed in Y. Hence $f$ is a $f g * p$ - closed map.

(c) $\Rightarrow$ (b): Let $\mathrm{f}$ be fg*p - continuous and fg*p-closed map. To prove that $\mathrm{f}$ is $f \mathrm{~g}^{*} \mathrm{p}$-open map. Let $\mathrm{U}$ be an open fuzzy set in $X$. Then $1-U$ is a closed fuzzy set in X. Since $f$ is fg*p - closed map, $f(1-U)$ is fg*p - closed in Y. Now $f(1-U)=1-f(U)$. 
Therefore $f(U)$ is $f g^{*} p$ - open in Y. Hence $f$ is $f g^{*} p$ - open map.

3.33 Theorem If $\mathrm{f}: \mathrm{X} \rightarrow \mathrm{Y} \mathrm{fg*p}$ - homeomorphism and g: $\mathrm{Y} \rightarrow \mathrm{Z}$ is fg*p- homeomorphism and $\mathrm{Y}$ is fuzzy $-\mathrm{T}_{\mathrm{p}}{ }^{*}$-space, then gof: $\mathrm{X} \square \rightarrow \mathrm{Z}$ is fg*p- homeomorphism.

Proof To show that gof and (gof) ${ }^{-1}$ are $f g^{*}$ semi continuous. Let $U$ be an open fuzzy set in $\mathrm{Z}$. Since $\mathrm{g}: \mathrm{Y} \rightarrow \mathrm{Z}$ is fg*p - continuous, $g^{-1}(U)$ is $f g^{*} p$-open in $Y$. Then $g^{-1}(U)$ is open fuzzy set in $\mathrm{Y}$ as $\mathrm{Y}$ is fuzzy- $\mathrm{T}_{\mathrm{p}}{ }^{*}$-space. Also since $\mathrm{f}$ : $\mathrm{X} \rightarrow \mathrm{Y}$ is fg*p- continuous, $\quad \mathrm{f}^{-1}\left(\mathrm{~g}^{-1}(\mathrm{U})\right)=(\mathrm{gof})^{-1}(\mathrm{U})$ is $\mathrm{g}^{*} \mathrm{p}-$ open in $\mathrm{X}$. Therefore gof is fg* $\mathrm{p}$ - continuous.

Again, let $\mathrm{U}$ be an open fuzzy set in $\mathrm{X}$.

Since $f^{-1}: Y \rightarrow X$ is $f g^{*} p$ - continuous, $\left.\left(f^{-1}\right)^{-1}(U)\right)=f(U)$ is $g^{*}$ p-open fuzzy set in $Y$. And so $f(U)$ is open fuzzy set in $Y$ as $\mathrm{Y}$ is fuzzy- $\mathrm{T}_{\mathrm{p}}{ }^{*}$-space. Also since $\mathrm{g}^{-1}: \mathrm{Z} \rightarrow \mathrm{Y}$ is fg*p continuous, $\left(\mathrm{g}^{-1}\right)^{-1}(\mathrm{f}(\mathrm{U}))=\mathrm{g}(\mathrm{f}(\mathrm{U}))=(\mathrm{gof})(\mathrm{U})$ is $\mathrm{g}^{*}$-open fuzzy set in Z. Therefore $\left((\text { gof })^{-1}\right)^{-1}(U)=($ gof $)(U)$ is $g^{*}$ p-open fuzzy set in $\mathrm{Z}$. Hence (gof) ${ }^{-1}$ is fg*p - continuous. Thus gof is fg*p - homeomorphism.

\section{CONCLUSION}

These mappings discussed above with counter examples is an interesting exercise to work in fuzzy topology spaces.

\section{ACKNOWLEDGMENTS}

The authors are grateful to the University Grants Commission, New Delhi, India for its financial support under UGC SAP I to the Department of Mathematics, Karnatak University, Dharwad, India and also for UGC-Research Fellowship under RFSMS Scheme, to the second author.

\section{REFERENCES}

[1] K.K. Azad, On fuzzy semi-continuity, fuzzy almost continuity and fuzzy weakly continuity, J. Math. Anal. Apl. 82(1981), 14-32.

[2] G. Balasubramanian and P. Sundaram, On some generalizations of fuzzy continuous, Fuzzy Sets and Systems, 86 (1997), 93-100.

[3] A. S. Bin Shahna, on fuzzy strong continuity and fuzzy precontinuity, Fuzzy Sets and Systems, 44 (1991), 303-308.

[4] C.L.Chang, Fuzzy topological spaces, J. Math. Anal. Appl. (1968), 182-190.

[5] M.Ferraro and D.H.Foster, Differentiation of fuzzy continuous mappings on fuzzy topological spaces. Jl. Math. Anal. Appl. 121 (1987), 589-601.

[6] T.Fukutake, R.K.Saraf, M.Caldas and S.Mishra, Mappings via Fgp-closed sets, Bull. of Fukuoka Univ. of Edu. Vol. 52, Part III (2003), 11-20.

[7] N.Levine, Generalized closed sets in topology, Rend. Circ. Mat. Palermo 19 (2) (1970), 89-96.

[8] S.R.Malghan and S.S.Benchalli, Open maps, closed maps and Local compactness in Fuzzy topological spaces, Jl. Math. Anal. Appl. 99 No. 2 (1984), 74-79.

[9] M.N.Mukherjee and B.Ghosh, Some stronger forms of fuzzy continuous mappings on fuzzy topological spaces, Fuzzy Sets and Systems, 38 (1990), 375-387.

[10] A.Pushpalatha, Studies on generalizations of mappings in topological spaces, Ph.D Thesis, Bharathiar University Combatorw, (2000).

[11] S.S.Thankar and Surendra Singh, On fuzzy semipreopen sets and fuzzy semi-precontinuity, Fuzzy Sets and Systems, 98 (1998), 383-391.

[12] M.K.R.S.Veerakumar, g\#-semi-closed sets in topology, Acta ciencia Indica, Vol. xxix M, No.1, 081 (2002).

[13] L.A. Zadeh, Fuzzy sets, Inform. and Control, 8 (1965), 338-353. 